\title{
Implant isolation of both n-type InP and InGaAs by iron irradiation: Effect of post-implant annealing temperature
}

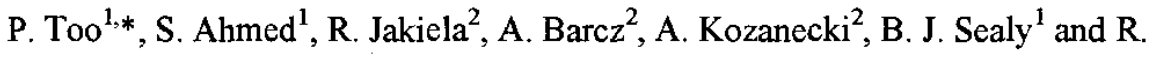 \\ Gwilliam $^{1}$
}

\author{
${ }^{1}$ Advanced Technology Institute, School of Electronics and Physical Sciences, University of \\ Surrey, Guildford, GU2 7XH, UK. \\ ${ }^{2}$ Institute of Physics, Polish Academy of Sciences, Al. Lotnikow 32/46, 02-668, Warsaw, \\ Poland.
}

\begin{abstract}
$1 \mathrm{MeV} \mathrm{Fe}^{+}$was implanted into n-type InP and $\mathrm{InGaAs}$ layers at different substrate temperatures, $-196^{\circ} \mathrm{C}$, room temperature (RT), $100^{\circ} \mathrm{C}$ and $200^{\circ} \mathrm{C}$ to obtain highresistivity regions. The sheet resistivity of the $\mathrm{InP}$ and $\mathrm{InGaAs}$ epilayers grown on semiinsulating (SI) InP substrates was measured as a function of substrate temperature and post-implantation annealing temperature $\left(100-800^{\circ} \mathrm{C}\right)$. For InP, a maximum sheet resistivity of $\sim 1 \times 10^{7} \Omega / \square$ was achieved for samples implanted at $-196^{\circ} \mathrm{C}$, RT and $100^{\circ} \mathrm{C}$ after annealing at $400^{\circ} \mathrm{C}$. For InGaAs samples, a maximum sheet resistivity of $1 \times 10^{7}$ and $2.3 \times 10^{6} \Omega / \square$ is obtained for $-196^{\circ} \mathrm{C}$ and RT implants respectively after annealing at $650^{\circ} \mathrm{C}$ for $60 \mathrm{~s}$. In both InP and InGaAs, the isolated regions exhibit good stability to heat treatment up to $500^{\circ} \mathrm{C}$ for all cases irrespective of the irradiation temperature. The iron depth profile obtained by secondary ion mass spectrometry (SIMS) shows that iron does not diffuse up to an annealing temperature of $550^{\circ} \mathrm{C}$ in both $\mathrm{InP}$ and InGaAs for all implantation temperatures. These results are novel since high sheet resistivity $\left(\sim 5 \times 10^{6}\right.$ $\Omega / \square)$ is obtained in both InP and InGaAs samples implanted at $-196^{\circ}$ and RT, and annealed at $400^{\circ} \mathrm{C}$. These data demonstrate the potential usefulness of iron implantation for isolation of $\mathrm{InP} / \mathrm{InGaAs}$ based devices.
\end{abstract}

\section{Introduction}

In bulk InP and InGaAs materials, highly resistive behaviour is usually obtained by doping the crystal with $\mathrm{Fe}$ during the growth. Fe atoms occupy In sites and act as deep acceptor centres for free electrons [1]. In epitaxial materials, the achievement of SI behaviour in selected areas is of crucial importance for lateral device isolation in integrated circuits and for the realisation of laser devices with current blocking regions beside the active region [2]. Thus ion implantation is an obvious candidate to selectively obtain SI regions in InP and InGaAs. With the increasing use of InGaAs and InP layers in heterojunction devices, there is a critical need to understand the behaviour of these materials upon ion bombardment for isolation purposes. The resistive behaviour can be due to the damage related levels introduced with the implant and/or to chemical compensation due to the implanted species (typically $\mathrm{Fe}$ or other transition metals) [3]. In $\mathrm{n}^{+}$InP and especially $\mathrm{n}^{+}$InGaAs, very low sheet resistivity $\left(\sim 10^{4} \Omega / \square\right)$ was reported by several authors after implantation of light ion species such as proton, helium, boron and nitrogen $[4,5,6]$. Isolation was mainly caused by a damage-induced compensation mechanism. In an effort to obtain higher sheet resistivities in n-type materials, we have *Fax : +44 1483689404, E-mail: p.too@surrey.ac.uk 
investigated the implantation of $\mathrm{Fe}$, an impurity which is known to result in highresistivity InP when used as a dopant during the growth of bulk crystals [7]. Many authors in the past reported on anomalous behaviour of iron during annealing $[8,9,10]$. It seems to diffuse rapidly within the implanted layer gettering at the surface and at the damaged regions. These authors claim that high resistivity behaviour cannot be achieved by $\mathrm{Fe}$ implantation on initially $\mathrm{n}^{+}$doped layers.

The formation of good and thermally stable electrical isolation in Si-doped InP and InGaAs layers using $1 \mathrm{MeV}$ iron at different substrate temperatures is studied in this work.

\section{Experimental Procedure}

Semi-insulating $\mathrm{Fe}$-doped InP wafers of (100) orientation were used as substrates for the growth of both n-type InGaAs and InP epilayers, with the (100) axis $2^{0}$ off normal orientation, using a Solid Source Molecular Beam Epitaxy (SSMBE) reactor. The n-type epilayers were doped with silicon with a concentration and thickness of $1 \times 10^{18} \mathrm{~cm}^{-3}$ and $1 \mu \mathrm{m}$ respectively. The wafers were cleaved to obtain several samples of approximately 1 $\mathrm{cm}^{2}$ for the preparation of the resistors. All samples were cleaned in organic solvents and the clover-leaf pattern was printed on them using optical lithography. The area of InP and InGaAs samples not covered with photoresist was etched to a depth of approximately $3 \mu \mathrm{m}$ using standard etching solutions. The photoresist was then removed in acetone leaving the cloverleaf Hall pattern on the samples.

The samples were divided into four different groups with implant isolation at temperatures of $-196^{\circ} \mathrm{C}, \mathrm{RT}, 100^{\circ} \mathrm{C}$, and $200^{\circ} \mathrm{C}$ using a $2 \mathrm{MV}$ High Voltage Engineering Europa (HVEE) implanter. For $-196^{\circ} \mathrm{C}, 100^{\circ} \mathrm{C}$ and $200^{\circ} \mathrm{C}$ implants, the samples were mounted on a special temperature control stage. The centre of the Hall pattern for all the samples was irradiated with $\mathrm{Fe}^{+}$using a dose and energy of $5 \times 10^{14} \mathrm{~cm}^{-2}$ and $1 \mathrm{MeV}$ respectively, with a beam current density $<0.33 \mu \mathrm{A} / \mathrm{cm}^{2}$. The post-implant annealing was performed in the range $100^{\circ} \mathrm{C}-800^{\circ} \mathrm{C}\left( \pm 5^{\circ} \mathrm{C}\right)$ for a time of $60 \mathrm{~s}$ in a nitrogen atmosphere, following a ramp up time of $60 \mathrm{~s}$ to temperature. Ohmic contacts to the samples were fabricated by applying indium and sintering at approximately $200^{\circ} \mathrm{C}$ for $2 \mathrm{~min}$. The sheet resistivity, was measured using a Bio-Rad HL5500 Hall effect system employing Van der Pauw geometry at $300 \mathrm{~K}$ under a magnetic field strength of $0.32 \mathrm{~T}$. All measurements were done at RT for samples implanted at $77 \mathrm{~K}, 100^{\circ} \mathrm{C}$ and $200^{\circ} \mathrm{C}$. The Fe depth profiles of the implant isolated samples were obtained by SIMS using a CAMECA IMS6f instrument. It was used to follow the diffusion behaviour of iron at different annealing temperatures. A $12.5 \mathrm{keV} \mathrm{O}_{2}^{+}$primary beam was used to monitor ${ }^{56} \mathrm{Fe}^{+}$in both $\operatorname{InP}$ and $\mathrm{InGaAs}$, analysing the $50 \mu \mathrm{m}$ diameter central part of a $150 \mu \mathrm{m}$ $\mathrm{x} 150 \mu \mathrm{m}$ crater.

\section{Results and Discussion}

The projected range of $1 \mathrm{MeV}$ iron in $\mathrm{InP}$ and $\mathrm{InGaAs}$ is about $0.6 \mu \mathrm{m}$ and $0.4 \mu \mathrm{m}$ respectively. The energy of $1 \mathrm{MeV}$ for the iron beam is chosen to place most of the iron atoms well inside the doped layer. In this way, the chemical compensation will be more effective for the electrical isolation of the InP and InGaAs epilayers. The effect of postimplant annealing temperature on n-type InP samples for the four different substrate temperatures is shown in figure 1. The initial sheet resistivity of the n-type InP layer for all the samples is $\sim 15 \Omega / \square$. After iron implantation, an as-implanted sheet resistivity of $\sim 5 \times 10^{6} \Omega / \square$ is obtained for substrate temperatures of $-196^{\circ} \mathrm{C}$, RT, and $100^{\circ} \mathrm{C}$ and that of 
$200^{\circ} \mathrm{C}$ is $7 \times 10^{5} \Omega / \square$. Thus there is an increase in the sheet resistivity by almost five orders of magnitude. After annealing the samples at $400^{\circ} \mathrm{C}$ for $60 \mathrm{~s}$, a maximum sheet resistivity of $\sim 1 \times 10^{7} \Omega / \square$ is reported for $-196^{\circ} \mathrm{C}$, RT and $100^{\circ} \mathrm{C}$ substrate temperatures and that for $200^{\circ} \mathrm{C}$ implantation temperature is $\sim 2 \times 10^{6} \Omega / \square$. The sheet resistivity decreases above $400^{\circ} \mathrm{C}$ but it increases again at $650^{\circ} \mathrm{C}$ to $2.1 \times 10^{6}, 1.2 \times 10^{6}$ and $2.6 \times 10^{5}$ $\Omega / \square$ for $-196^{\circ} \mathrm{C}$, RT and $100^{\circ} \mathrm{C}$ implants respectively. This effect is not observed for samples implanted at $200^{\circ} \mathrm{C}$. The high sheet resistivity $\left(10^{6}-10^{7} \Omega / \square\right)$ is maintained until an annealing temperature of $500^{\circ} \mathrm{C}$ for all four substrate temperatures. This wide thermally stable annealing window is extremely important from the technological point of view.

We believe that the isolation for iron implantation into InP is a combination of both damage and chemical compensation. The deep acceptor level of $\mathrm{Fe}$ on an indium site is responsible for the chemical compensation as observed in grown semi-insulating InP [1]. This Fe deep level acceptor is annealed out at $600^{\circ} \mathrm{C}$ as reported by Kadoun et al [11]. Hence the decrease in the sheet resistivity observed at $600^{\circ} \mathrm{C}$ is believed to be the annealing of this defect level. The increase in sheet resistivity again at $650^{\circ} \mathrm{C}$ is believed to be due to a phosphorus vacancy-iron $\left(\mathrm{V}_{\mathrm{p}}-\mathrm{Fe}\right)$ complex defect which is formed above an annealing temperature of $600^{\circ} \mathrm{C}$. Kadoun et al [11] reported similar complex defects in InP for annealing temperatures between $600^{\circ} \mathrm{C}$ and $700^{\circ} \mathrm{C}$. One possible explanation for not observing this effect for $200^{\circ} \mathrm{C}$ implants is due to annealing of most of the $\mathrm{V}_{\mathrm{p}}$ defects so that the complex defect responsible for the high sheet resistivity is less likely to be formed. The lower sheet resistivity obtained for $200^{\circ} \mathrm{C}$ implants as compared to $196^{\circ} \mathrm{C}, \mathrm{RT}$ and $100^{\circ} \mathrm{C}$ implants is most probably due to a lower defect concentration as a result of enhanced dynamic annealing. Many of the defects created at such an elevated temperature are annealed out or do not form during the implantation. We reported that for a high dose $\left(5 \times 10^{14} \mathrm{~cm}^{-2}\right)$, lower damage is obtained for higher substrate temperatures [12]. Above $700^{\circ} \mathrm{C}$, there is a gradual decrease in sheet resistivity for all the substrate temperatures due to recovery of the carriers as the defects are annealed out and the iron diffuses out of the doped region (see SIMS data below).

Similar experiments to those just described were also carried out on $\mathbf{n}^{+}$InGaAs epilayers which had an initial sheet resistivity $\sim 32 \Omega / \square$. Figure 2 shows the change in the sheet resistivity as a function of post-implant annealing temperature which is similar in form to the results for InP (figure 1). A maximum sheet resistivity of $1 \times 10^{7}$ and $2.3 \times 10^{6} \Omega / \square$ is obtained for $-196^{\circ} \mathrm{C}$ and RT implants respectively after annealing at $650^{\circ} \mathrm{C}$ for $60 \mathrm{~s}$. In the case of $100^{\circ} \mathrm{C}$ and $200^{\circ} \mathrm{C}$ implants, the maximum isolation is only $\sim 1 \times 10^{5} \Omega / \square$ after annealing at $550^{\circ} \mathrm{C}$. Similar to $\operatorname{InP}$ isolation results, the increase in the sheet resistivity for $-196^{\circ} \mathrm{C}$ and $\mathrm{RT}$ implanted samples at $650^{\circ} \mathrm{C}$ is most probably due to the formation of complex defects related to $\mathrm{Fe}$ atoms. As shown in figure 2, the sheet resistivity for $196^{\circ} \mathrm{C}$ implants is only two times higher than that of RT implants for samples annealed in the range of $100^{\circ} \mathrm{C}-500^{\circ} \mathrm{C}$. Since all samples implanted at $-196^{\circ} \mathrm{C}$ are measured at RT, a certain amount of annealing of defects may take place when the sample is brought up to room temperature, which may affect the isolation behaviour of the samples. We infer that many of the defects formed at $-196^{\circ} \mathrm{C}$ are annealed out as the samples are warmed up to room temperature. A lower electrical isolation is obtained for hot implants compared to $-196^{\circ} \mathrm{C}$ and RT implants. This is most probably due to less damage production during hot implants due to enhanced dynamic annealing. Beyond the postimplant annealing temperature where maximum isolation is obtained for all substrate temperatures, the sheet resistivity decreases gradually towards its original value. This 
suggests - that most of the defects are annealed out and that out-diffusion of $\mathrm{Fe}$ at temperatures between $700-800^{\circ} \mathrm{C}$ occurs as shown by SIMS measurements (see below).

Figures 3-6 show the SIMS Fe depth profiles of $-196^{\circ} \mathrm{C}$ and $200^{\circ} \mathrm{C}$ implants for InP and InGaAs samples which have been annealed in the range of $100^{\circ} \mathrm{C}$ to $800^{\circ} \mathrm{C}$. The detection limit for iron in both InP and InGaAs is $2-3 \times 10^{15} \mathrm{~cm}^{-3}$. The silicon signal is also monitored during the SIMS measurements, showing the expected flat doping profile without any particular feature that could be related to those observed for the $\mathrm{Fe}$ signal (figure 3). An abrupt interface between the silicon doped layer and the substrate is observed for all samples. The $\mathrm{Fe}$ depth profile of the $-196^{\circ} \mathrm{C}$ implants fits the TRIM profile quite well, but for the $200^{\circ} \mathrm{C}$ implants, broadening of the SIMS profile is observed at the tail. One possible explanation of this broadening is the increased mobility of the iron during elevated temperature implants as a result of radiation enhanced diffusion: Also during $200^{\circ} \mathrm{C}$ implantation, the dynamic interaction of defects with the injected iron could be another reason behind the tail broadening. The Fe profile for $\mathrm{InP}$ and InGaAs samples annealed up to $650^{\circ} \mathrm{C}$ and $550^{\circ} \mathrm{C}$ respectively, is similar to the as-implanted profile for all substrate temperatures. In the case of InP, at an annealing temperatures as high as $800^{\circ} \mathrm{C}$, only a limited amount of $\mathrm{Fe}$ atoms diffuse from the deeper side of the $\mathrm{Fe}$ peak towards the doped layer-substrate interface for $-196^{\circ} \mathrm{C}$ implants (figure 3 ). No strong iron diffusion or accumulation peaks are observed at this implantation temperature. For InP samples implanted at $200^{\circ} \mathrm{C}$, the iron profile broadens during annealing at $700^{\circ} \mathrm{C}$ and $800^{\circ} \mathrm{C}$. The tail of the broadened profile extends up to $1 \mu \mathrm{m}$ inside the substrate (figure 4). For InGaAs samples, above an annealing temperature of $650^{\circ} \mathrm{C}$, iron atoms redistribute towards the surface and the interface between the InGaAs epilayer and the InP substrate (figure 5 and 6 ). These results are consistent with the decrease in the sheet resistivity observed from figure 2 .

We believe that the immobility of iron in InP at such a high annealing temperature is due to the Si retarding effect on $\mathrm{Fe}$ diffusion. The $\mathrm{Fe}$ diffusion mechanism in InP is not completely understood, although it is believed that Fe diffuses with an interstitial substitutional mechanism [13]. This diffusion mechanism involves the migration of iron atoms from an interstitial position to a neighbouring substitutional one. Hence the presence of $\mathrm{Si}$ atoms on substitutional sites will reduce the vacant sites available for diffusion of Fe. Van Gurp et al [14] have observed a similar retarding effect for zinc diffusion in silicon doped InP. They reported a decrease in the diffusion of zinc with an increase in the silicon doping concentration.

\section{Conclusion}

A technologically relevant study of an isolation scheme using iron into n-type InP and InGaAs at various substrate temperatures has been made. The substrate temperature during implantation is found to play an important role for maximum electrical isolation and improved thermal stability of the isolation after post-implant annealing. $\mathrm{Fe}^{+}$ implantation at $-196^{\circ} \mathrm{C}$ in both n-type InP and InGaAs is reported to provide high sheet resistivity without 'any diffusion of $\mathrm{Fe}^{+}$until an annealing temperature of $650^{\circ} \mathrm{C}$. The immobility of iron is a great advantage since the effect of Fe on the device performance will be insignificant. These results are novel from the device engineering point of view and may have some useful applications for $\operatorname{InP} / \mathrm{InGaAs}$ device isolation. 


\section{Acknowledgements}

The authors gratefully acknowledge financial support from the UK Engineering and Physical Sciences Research Council (EPSRC). We would also like to thank the staff at the Sheffield III-V facility for the growth of the epilayers.

\section{References:}

[1] S. Fung, R. J. Nicholas, and R. A. Stradling, A study of the deep acceptor levels of iron in InP, J. Phys. C (1979) 12, 5145.

[2] M. V. Rao, High-energy (MeV) ion implantation and its device applications in GaAs and InP, IEEE Trans. Elec. Dev. (1979) 40, 1053.

[3] S. J. Pearton, Ion implantation for isolation of III-V semiconductors, Mater. Sci. Rep. (1990) 4, 313.

[4] J. P. Donnelly, and C. E. Hurwitz, Proton bombardment in InP, Sol. Stat. Elec. (1977) 20,727.

[5] B. Tell, K. F. Brown-Goebeler, T. J. Bridges, and E. G. Burkhardt, Resistance and mobility changes in InGaAs produced by light ion bombardment, $J$. Appl. Phys. (1986) 60,665.

[6] P. Too, S. Ahmed, R. Gwilliam, and B. J. Sealy, Implant isolation of InP and InGaAs by proton irradiation at variable doses and substrate temperatures, IEEE Intl. Symp. on Elec. Dev. Micro. Opto. Appl. (EDMO, Vienna) (2001) 125.

[7] O. Mizuno, and H. Watanabe, Semi-insulating properties of Fe-doped InP, Elec. Lett. (1975) 11, 118.

[8] J. Vellanki, R. K. Nadella, M. V. Rao, O. W. Holland, D. S. Simons, and P. H. $\mathrm{Chi}, \mathrm{MeV}$ energy $\mathrm{Fe}$ and $\mathrm{Co}$ implants to obtain buried high-resistance layers and to compensate donor implant tails in InP, J. Appl. Phys. (1993) 73, 1126.

[9] S. J. Pearton, C. R. Abernathy, M. B. Panish, R. A. Hamm, and L. M. Lunardi, Implant induced high-resistivity regions in InP and InGaAs, J. Appl. Phys. (1989) 66, 656.

[10] S. A. Schwartz, B. Schwartz, T. T. Sheng, S. Singh, and B. Tell, Annealing behaviour of ion-implanted Fe in InP, J. Appl. Phys. (1985) 58, 1698.

[11] A. Kadoun, G. Marrakchi, A. Kalboussi, D. Barbier, and G. Guillot, Study of deep level defect behaviour in rapid thermal annealed Fe-doped semiinsulating InP, Mat. Sci. and Eng. B (1995) 33, 188

[12] P. Too, S. Ahmed, C. Jeynes, B. J. Sealy, and R. Gwilliam, Electrical isolation of $n$-type InP using $\mathrm{MeV}$ iron implantation at different doses and substrate temperatures, Elec. Lett. (2002) 38, 1225.

[13] B. Tuck, Mechanisms of atomic diffusion in the III-V semiconductors, $J$. Phys. D: Appl. Phys. (1985) 18, 557.

[14] G. J. Van Gurp, P. R. Boudewijn, M. N. C. Kempeners, and D. L. A. Tjaden, Zinc diffusion in n-type indium phosphide, J. Appl. Phys. (1987) 61, 1846. 


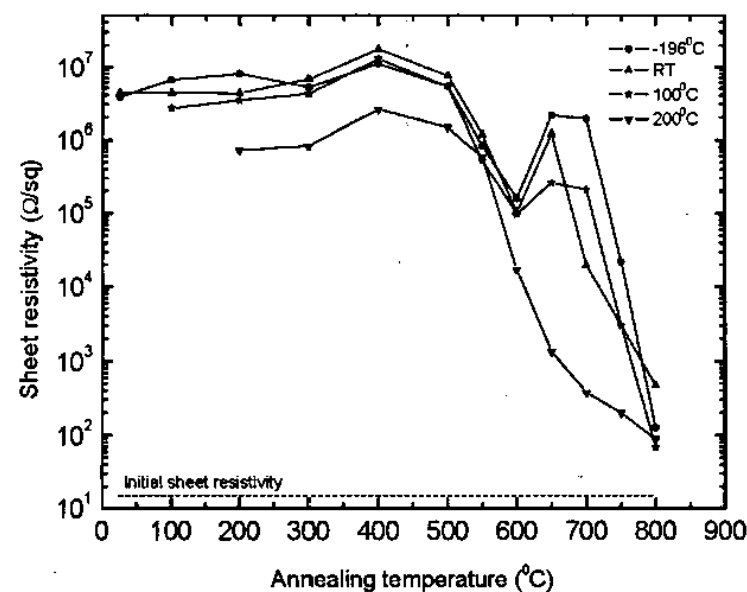

Figure 1: Evolution of sheet resistivity with different post-implant annealing temperature for $1 \mathrm{MeV}$ iron implanted n-type InP layers irradiated with $5 \times 10^{14} \mathrm{~cm}^{-2}$ at $-196^{\circ} \mathrm{C}, \mathrm{RT}, 100^{\circ} \mathrm{C}$ and $200^{\circ} \mathrm{C}$.

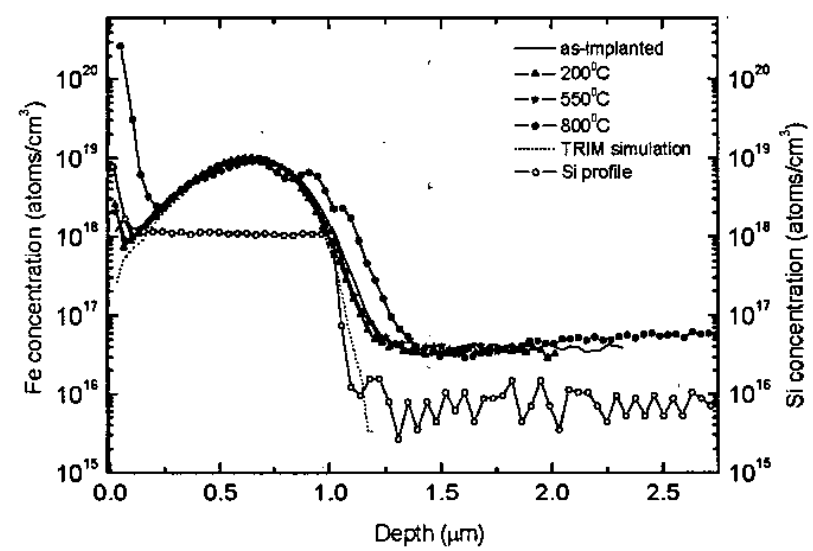

Figure 3: SIMS Fe profiles for InP samples implanted at $-196^{\circ} \mathrm{C}$ using a dose of $5 \times 10^{14} \mathrm{~cm}^{-2}$ for different annealing temperatures. Si and TRIM Fe profile is also plotted on the same graph.

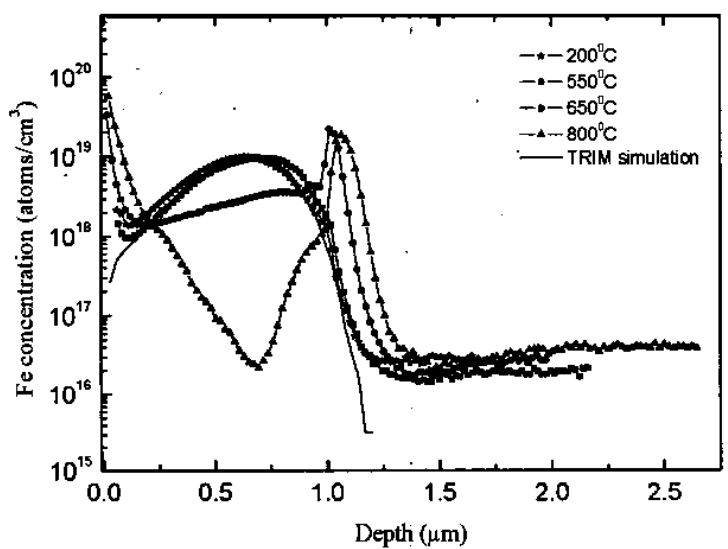

Figure 5: SIMS Fe profiles for InGaAs samples implanted at $-196^{\circ} \mathrm{C}$ using a dose of $5 \times 10^{14} \mathrm{~cm}^{-2}$ for different annealing temperatures. TRIM Fe profile is also plotted on the same graph.

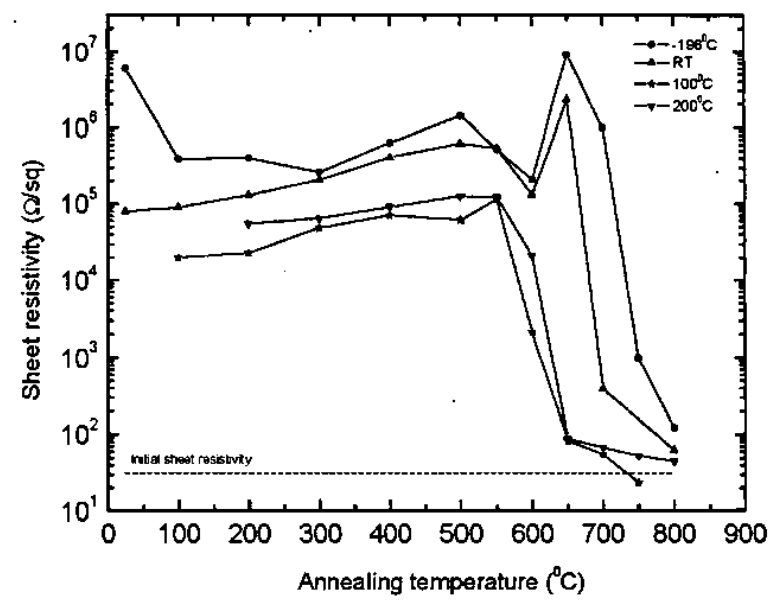

Figure 2: Evolution of sheet resistivity with different post-implant annealing temperature for iron implanted n-type InGaAs layers irradiated with $5 \times 10^{14} \mathrm{~cm}^{-2}$ at $1 \mathrm{MeV}$ at $-196^{\circ} \mathrm{C}, \mathrm{RT}, 100^{\circ} \mathrm{C}$ and $200^{\circ} \mathrm{C}$.

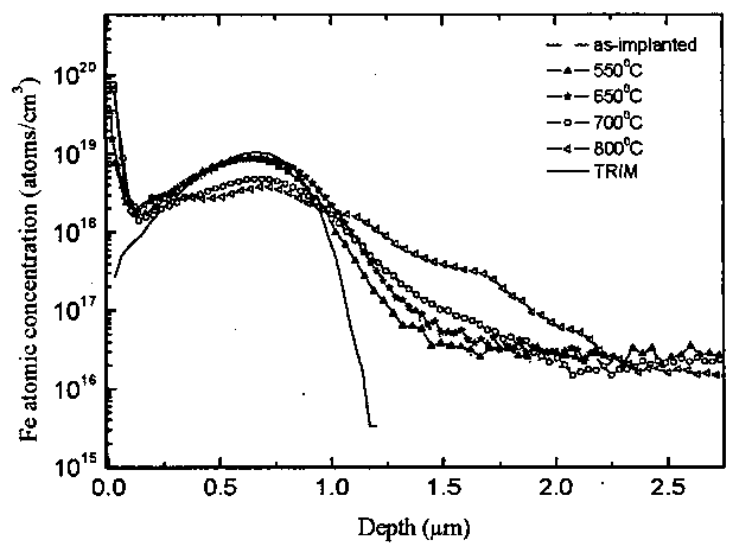

Figure 4: SIMS Fe profiles for InP samples implanted at $200^{\circ} \mathrm{C}$ using a dose of $5 \times 10^{14} \mathrm{~cm}^{-2}$ for different annealing temperatures. TRIM Fe profile is also plotted on the same graph.

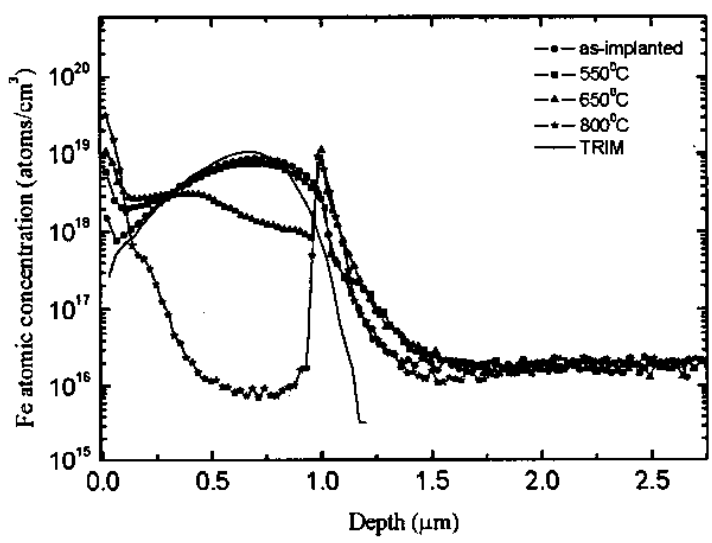

Figure 6: SIMS Fe profiles for InGaAs samples implanted at $200^{\circ} \mathrm{C}$ using a dose of $5 \times 10^{14} \mathrm{~cm}^{-2}$ for different annealing temperatures. TRIM Fe profile is also plotted on the same graph. 